\title{
Cholesterol Homeostasis Imbalance and Brain Functioning: Neurological Disorders and Behavioral Consequences
}

\section{Lecis $\mathrm{C}^{1}$ and Segatto $\mathrm{M}^{{ }^{2}}$}

${ }^{1}$ Department of Experimental Medicine and Surgery, University of Rome "Tor Vergata", Rome, Italy

${ }^{2}$ Department of Biosciences, University of Milan, Milan, Italy

*Corresponding author: Segatto M, Department of Biosciences, University of Milan, via Celoria 26, 20133, Milan, Italy, Tel: +39- 0250314989, E-mail: marco.segatto@uniroma3.it

Citation: Lecis C, Segatto M (2014) Cholesterol Homeostasis Imbalance and Brain Functioning: Neurological Disorders and Behavioral Consequences. J Neurol Neurol Disord 1(1): 101. doi: 10.15744/24544981.1.101

Received Date: April 09, 2014 Accepted Date: December 22, 2014 Published Date: December 29, 2014

\begin{abstract}
Cholesterol is an amphipathic sterol compound that exerts both structural and physiological tasks in the plasma membrane of all eukaryotic cells. The planar and rigid structure of this molecule regulates the fluidity of the phospholipid bilayer and its permeability to solutes and ions. The structural role of cholesterol is particularly relevant in the central nervous system, where it represents one of the major components of myelin sheaths, and an important constituent of the synaptic vesicle membranes. The synthesis and trafficking of cholesterol is highly specialized in the brain, and displays several differences if compared to its metabolism in other tissues. In humans, disruption to cholesterol homeostasis can lead to a wide spectrum of pathological conditions. The relevance of this compound in the pathogenesis of atherosclerosis and other cardiovascular diseases is nowadays well established, while correlations existing between cholesterol and brain disorders are still poorly characterized. Therefore, the aim of this review is to summarize the current knowledge that links alterations of cholesterol homeostasis with the onset and the progression of several neurological and neuropsychiatric disorders.

Keywords: Cholesterol; Central Nervous System; Neurological disorders; Neuropsychiatric disorders

List of abbreviations: CNS: Central Nervous System; TGs: Triglycerides; CMs: Chylomicrons; VLDLs: Very Low-Density Lipoproteins; LDLs: Low-Density Lipoproteins; HDLs: High-Density Lipoproteins; LPL: Lipoprotein lipase; Apo: Apolipoprotein; MVA: Mevalonate; ABC: ATP Binding Cassette; ER: Endoplasmic Reticulum; HMGR: $3 \beta$-Hydroxy-3 $\beta$-Methylglutaryl CoA Reductase; LDLr: LDL receptor; AMPK: AMP activated protein Kinase; PP2A: Protein Phosphatase 2A; SREBPs: Sterol Regulatory Element Binding Proteins; SCAP: SREBP Cleavage Activating Protein; INSIG: Insulin Induced Gene; BBB: Blood-Brain Barrier; LRP1: LDLr-Related Protein 1; LXRs: Liver X Receptors; AD: Alzheimer's Disease; A $\beta$ : Amyloid $\beta$; NFTs: Neurofibrillary Tangles; APP: Amyloid Precursor Protein; BACE 1: Beta-site APP Cleaving Enzyme 1; FAD: Familial AD; ACAT: Acyl-coenzymeA: Cholesterol Acyl-Transferase; PROSPER: PROspective Study of Pravastatin in the Elderly at Risk; NPC disease: Niemann-Pick type C disease; HD: Huntington's Disease; HTT: Huntingtin protein; SLOS: Smith-Lemli-Opitz Syndrome; ASD: Autism Spectrum Disorders; 7-DHC: 7-Dehydrocholesterol; DHCR7: 7-Dehydrocholesterol Reductase; RTT: Rett Syndrome; MeCP2 Methyl-CpG-binding Protein 2
\end{abstract}

\section{Introduction}

Cholesterol is a 27-carbon sterol compound with amphipathic properties that exerts both structural and physiological functions in the human body. It is an essential component of the plasma membrane of all eukaryotic cells, and also serves as a precursor for the biosynthesis of bile acids, steroid hormones, and vitamin D [1,2]. This role is emphasized in the central nervous system (CNS), where a proper membrane structure is necessary for the propagation of saltatory impulse along the axon and in the synaptic connectivity between neurons [3]. Cholesterol is also implicated in the formation of specialized membrane microdomains (lipid rafts) and in the vesicular trafficking of substances across the cytosol [4].

Inherited or acquired alterations of cholesterol homeostasis can lead to a wide spectrum of pathological conditions. Although the role of this compound in the pathogenesis of atherosclerosis and other life-threatening cardiovascular diseases (such as acute coronary syndrome) is well established [5], correlations existing between cholesterol and CNS disorders are still poorly characterized. Thus, the aim of this review is to summarize the current knowledge obtained from the analysis of clinical and experimental data that links cholesterol imbalance with the onset and the progression of several neurological and neuropsychiatric disorders.

\section{Overview of cholesterol metabolism in the human body}

Before discussing cholesterol homeostasis in the CNS, it is useful to summarize the major regulatory mechanisms occurring in other tissues, as some of these pathways are also relevant in the CNS. 
In eukaryotic cells, most cholesterol is located in either the outer and inner leaflet of the plasma membrane, whereas a smaller amount of this sterol is found in the intracellular membranes of the endoplasmic reticulum (ER), Golgi apparatus and in the nucleus [3]. In the plasma membrane, this abundant pool of unesterified cholesterol is important for the maintenance of the architectural characteristics of the cell, and its concentration is therefore tightly regulated.

Cholesterol requirement is assured by two different mechanisms: food intake and de novo biosynthesis. Following a meal, the enterocytes in the small intestine produce chylomicrons (CMs) and, to a lesser extent, very low density lipoproteins (VLDLs) [6,7]. CMs are lipoproteic particles that significantly transport more triglycerides (TGs) than VLDLs, and a number of studies suggest that intestinal CMs and VLDLs are produced by two differential pathways [8]. CMs are secreted to lymph for delivery into the blood circulatory system. Once into the bloodstream, TGs are hydrolyzed through the activity of vascular lipoprotein lipase (LPL), and delivered to peripheral tissues. The enriched CM remnants are then taken up by the hepatocytes. In the liver, cholesterol serves as a precursor for bile acid biosynthesis or is incorporated again into hepatic VLDL particles, which are released into the systemic circulation. These particles become LDLs after a partial depletion in TGs, which is mediated by the vascular LPL activity. LDL is responsible for cholesterol delivery to peripheral tissues, whereas high density lipoproteins (HDLs) are involved in the inverse transport of cholesterol. Notably, apolipoprotein (apo) A1 and apoA2 proteins, which are incorporated into HDLs, serve as cholesterol acceptors and efficiently catch this lipid from peripheral tissues. On the other hand, cellular uptake of lipids is assured by the presence of apoB100 and apoE, which are incorporated into VLDLs and LDLs and constitute the ligands for LDL receptor (LDLr): this receptor-mediated endocytosis is the primary source of lipids for extra-hepatic tissues and represents one of the most outstanding pathways in regulating the import of cholesterol [9]. The excess of intracellular cholesterol is exported through the membrane expression of ATP-binding cassette (ABC) transporter superfamily and the extracellular presence of apolipoproteins as free cholesterol acceptors. At the level of the whole organism, the excess of cholesterol is converted into bile acids, and then eliminated in the faeces. This exclusive mechanism of excretion is further regulated by the enteroepathic cycle of bile acids (i.e., excretion in the gut lumen, subsequent absorption in the ileum and ingression into the liver), and is partially directed to save complex and energy-costly compounds, such as cholesterol and bile acid derivatives [10]. On the contrary, when cholesterol levels are low, de novo biosynthesis is highly activated.

Dietary intake described above accounts for only 22\% of plasma cholesterol, whereas de novo biosynthesis is responsible for the remaining amount of this molecule [10]. Cholesterol is prevalently synthesized in the hepatic tissue, where the major part of its metabolism takes place. However other tissues, such as intestine, muscle and skin, are able to produce significant amounts of this sterol [11]. Isoprenoid/cholesterol biosyntethic pathway (Figure 1), also known as mevalonate (MVA) pathway, is a complex, multi-enzymatic process present in all eukaryotic cells. Besides cholesterol, it leads to the production of several other end-products indispensable for cell survival, such as isopentenyl tRNA, dolichol, farnesyl pyrophosphate, geranylgeranyl pyrophosphate and coenzime Q (CoQ) [12].

The $3 \beta$-hydroxy-3 $\beta$-methylglutaryl CoA reductase (HMGR) is an ER-associated membrane glycoprotein and represents the key and rate-limiting enzyme of the pathway that catalyzes the NADPH-dependent reduction of $3 \beta$-hydroxy-3 $\beta$-methylglutaryl CoA to MVA [13]. Due to its central role, this enzyme undergoes a fine regulation achieved by short- and long-term mechanisms. Phosphorylation/dephosphorylation cycles are responsible for the short-term regulation of the enzyme. AMP activated protein kinase (AMPK) inhibits HMGR activity by phosphorylating a specific serine residue (Ser872), whereas the removal of the phosphate group from the same aminoacidic residue, operated by the protein phosphatese $2 \mathrm{~A}$ (PP2A), is able to enhance the activity of the enzyme [14]. Aside from short-term regulation, HMGR is subjected to transcriptional, translational and post-translational control [15]. MVA pathway end-products, and cholesterol in particular, participate in a negative feedback response which determines the long-term regulation of the enzyme. When intracellular levels of cholesterol are low, the transcription of genes necessary for cholesterol synthesis and uptake is activated (e.g. HMGR and LDLr). This event is mediated by sterol regulatory elements binding proteins (SREBPs), a family of transcriptional factors which recognize and bind the sterol regulatory element (SRE) DNA sequences. SREBPs localize on ER membrane, as long as SREBP cleavage activating proteins (SCAP), which function as sterol sensors [16]. In sterol-deprived cells, SCAP binds SREBPs and escorts them from the ER to the Golgi apparatus, where SREBPs are proteolytically processed. These selective cleavages produce SREBP transcriptionally active fragments, that enter the nucleus and induce the expression of their target genes [17]. When cellular sterol content increases, the SCAP/SREBP complex is retained into the ER, the proteolytic processing of SREBPs is abolished and the transcription of target genes is blocked. ER retention of SCAP/ SREBP is mediated by the sterol-dependent binding of the complex to the ER-resident protein insulin induced gene (INSIG) [16]. In addition, the build-up of intracellular sterols also induces the interaction between INSIG and HMGR, thus promoting the ubiquitination and the subsequent proteasomal degradation of the enzyme [18].

Owing to its key role in cholesterol biosynthesis, HMGR has been considered a very attractive molecular target to treat lipid disorders. In particular, statins are the most prescribed cholesterol-lowering drugs in industrialized countries, where coronary diseases, consistent with hypercholesterolemia, represent the principal cause of death [19]. Due to their bulky hydrophobic structure, these drugs competitively impair the binding of HMG-CoA to its pocket within HMGR active-site, strongly inhibiting the enzyme activity [20]. 


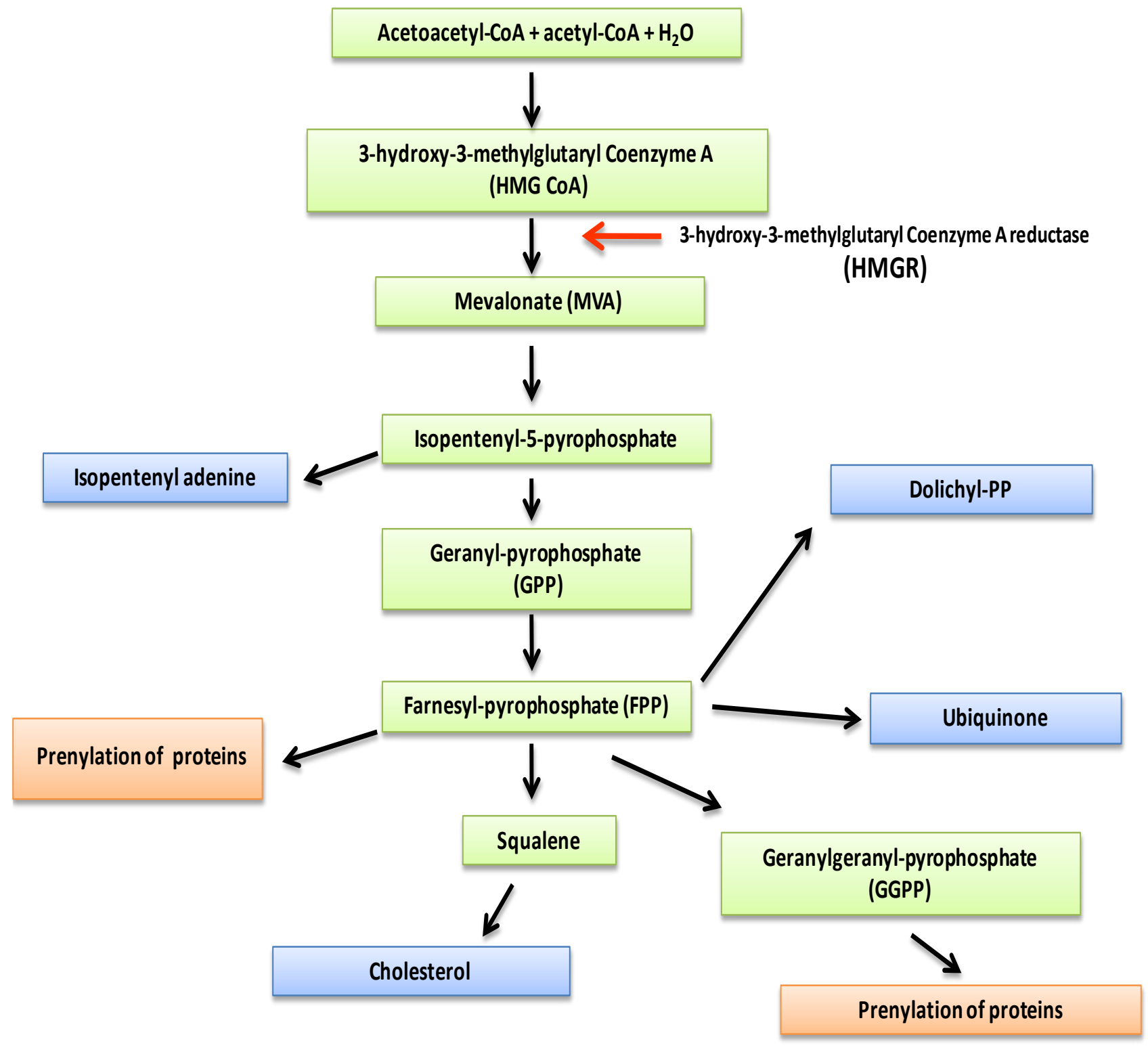

Figure 1: Main steps of isoprenoid/cholesterol biosynthetic pathway. The mevalonate (MVA) pathway is a metabolic pathway presents in all eukaryotic cells that leads to the production of several bioactive molecules, such as cholesterol, ubiquinone (coenzyme Q), isopentenyl adenine, dolichol and prenyls (farnesyl-pyrophosphate, geranylgeranyl-pyrophosphate, which serves for protein prenylation). The conversion of $3 \beta$-hydroxy$3 \beta$-methylglutaryl coenzymeA (HMG-CoA) into MVA is the rate-limiting step of this process, catalyzed by HMGR.

\section{Cholesterol metabolism in the CNS}

During evolution, the structural importance of cholesterol within cell membranes acquires an additional and highly specialized role in the CNS. Neuronal transmission of the impulse is assisted by myelin sheaths, membrane specializations derived from oligodendrocytes that wrap the axon of several neighboring neurons. These myelin sheaths are separated by periodic gaps, called nodes of Ranvier, which determine the discontinuous insulation of the axon and, as a result, the saltatory conduction of the action potential. Owing to cholesterol enrichment, myelin sheaths have a reduced permeability to ions, thus allowing the propagation of the electrical impulse along the axon rather than across the membranes of oligodendrocytes [21].

Cholesterol is also particularly abundant in synaptosomal membranes, influencing synapse formation, stability and neurotransmitter release. At pre-synaptic level, this molecule localizes prevalently in the inner leaflet of the lipidic bilayer, with a predominant structural role. In post-synaptic terminals, it functions as a constituent of lipid rafts, that anchors and regulates the activity of several neurotransmitter receptors (e.g. GABAa receptors and AMPA-type glutamate receptors) and other post-synaptic elements on the membrane [22-24]. Microtubular transport of synaptic vesicles within the cytosol, subsequent fusion and release via SNAREprotein interaction also depend on high cholesterol levels. Specifically, high cholesterol concentration is required for the correct membrane curvature and for the assembly of vesicle-specific proteins and lipids [25]. 
From these observations, it is not surprising that cholesterol requirement in the CNS is very high. Even though the CNS accounts for only $2.1 \%$ of body weight, it contains $23 \%$ of the total cholesterol pool found in the whole body. Almost all (at least $99 \%$ ) CNS cholesterol is present in an unesterified free form and is part of the myelin sheaths of oligodendrocytes (70\%) or of the plasma membranes of astrocytes and neurons [3]. Net movement of cholesterol and lipoproteins from systemic circulation to CNS, does not seem to occur significantly in mammals. The incapability to transport lipoprotein particles inside the CNS is due to the anatomical constitution of the blood-brain barrier (BBB). In different regions of the body, capillaries have different permeabilities that are determined by the presence of fenestrations, adherent junctional complexes, and transcellular vesicular transport [26]. Capillaries of the brain are characterized by tightly adherent junctions, absence of fenestrae and minimal bulky phase vesicular transport. Moreover, astrocytic foot processes are intimately associated with the inner or basal membranes of endothelial cells [27]. This specific architecture forms a high resistance barrier, where the net movement of several substances, including cholesterol, is limited or hindered.

Thus, in situ biosynthesis remains the major source of cholesterol within the CNS. According to studies performed on cell cultures, astrocytes synthesize at least 2- to 3-fold more cholesterol than neurons [28]. Besides the specific rate of cholesterol synthesis of diverse cell types in the CNS, recent observations also demonstrated that cholesterol uptake and biosynthesis is different among brain regions, and that both gender and aging are able to modify these metabolic processes [29]. Specifically, HMGR and LDLr show a peculiar expression pattern, in relation to the brain regional needs of cholesterol [30].

Almost all neurons depend on cholesterol produced by other cell types. A number of experimental evidence strongly suggests that cholesterol is produced by astrocytes and delivered to neurons (Figure 2) [31]. Notably, most part of synapses are formed after astrocyte differentiation during CNS development [32], when neurons are characterized by a very low expression of enzymes belonging to the cholesterol biosynthetic machinery compared to astroglia [33]. From these observations, CNS cell types appear to undergo specific metabolic specializations in vivo, reflecting a diverse regulation of cholesterol metabolism [34].

A widely accepted model for cholesterol homeostasis in the CNS suggests that during embryogenesis, before astrocyte differentiation, neurons ensure their cholesterol requirement by biosynthesis. Postnatally, neurons reduce or even abandon their own synthesis and import cholesterol from astrocytes. The physiological explanation for cholesterol biosynthesis suspension in neurons may be related to the high energy expenditure of this metabolic process, which consumes a number of energy metabolites and requires more than 20 dedicated enzymes. Thus, it would be more advantageous for neurons, in terms of energy costs, to use cholesterol delivered from astrocytes [31]. As a result, the intercellular transport of cholesterol from astrocytes allows neurons to preserve energy that could be employed for the generation of electrical activity [35]. This hypothesis is also supported by the evidence that astrocytes secrete cholesterol-rich particles. These apoE-containing lipoproteins are similar to LDLs found in the bloodstream. The uptake of apoE-rich lipoproteins is realized through the endocytosis mediated by LDLr family members, such as LDLr and LDLrrelated protein 1 (LRP1), whose expression is particularly high in neurons [31].

In addition to LDL receptor family members, $\mathrm{ABC}$ transporters play a central role in the flow of cholesterol from astrocytes to neurons. ABCA1 is highly expressed in astrocytes, where it mediates the transfer of intracellular and neo-synthetized cholesterol to extracellular lipid-free apoE [36]. For this reason, ABCA1 functions as a key element in cholesterol shuttle from glia to neurons through apoE-rich particles. ABCA1 is also crucially involved in the maintenance of brain cholesterol homeostasis, since it results to be a target gene of the nuclear liver X receptors (LXR)s. LXRs exert their function through a feed-forward mechanism, contributing to the control of intracellular amount of sterols. Experimental data demonstrated that mice lacking LXRs exhibit severe neurological defects, such as reduction in ventricle size, accumulation of lipids and apoE in different brain regions, and microvessel deformity. Furthermore, astrocytosis, neuron loss, and ultra-structural alterations in neurons and glial cells were also observed [37]. LXRs are specifically activated by 24(S)-hydroxycholesterol. This cholesterol derivative induces the increase of ABCA1 expression, and ultimately the efflux of cholesterol from astrocytes. 24(S)-hydroxycholesterol also represents the main cholesterol excretory pathway in the CNS. Indeed, unlike cholesterol, it is able to passively diffuse out of the cell and across the BBB. 24(S)-hydroxycholesterol is produced by the activity of cytochrome P-450 (CYP46A1), which was found to be highly expressed in neurons, indicating that the main excretion mechanism of cholesterol from the brain involves neuronal cells rather than glial cells [35].

\section{Imbalance of cholesterol metabolism and CNS disorders}

In view of the importance of this lipid in the CNS, it is not surprising that disturbances in cholesterol homeostasis have been associated to the onset and the development of several neurological and neuropsychiatric disorders. In the following paragraphs, the links between cholesterol imbalance and dysfunctional consequences in the CNS will be discussed.

\section{Alzheimer's disease}

Alzheimer's disease $(\mathrm{AD})$ is a neurological degenerative disorder characterized by a poor prognosis. The most well-known symptom is the progressive and consistent memory impairment. However, it is also clinically distinguished by acquired behavioral disturbances and mood changes. Biochemically, $\mathrm{AD}$ presents specific hallmarks, which are constituted by the build-up of abnormally folded amyloid $\beta(\mathrm{A} \beta)$ and tau proteins in the CNS [38]. 


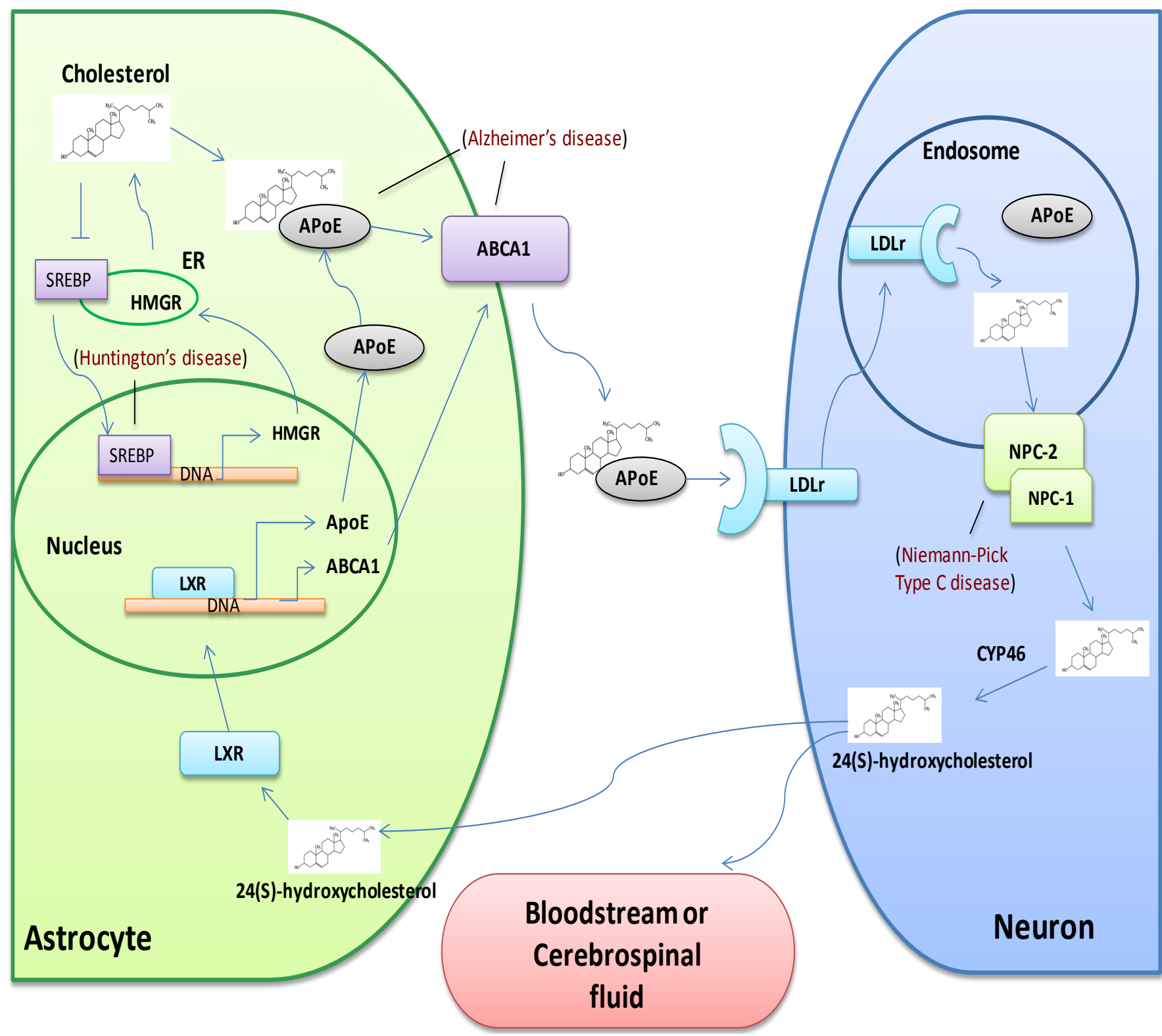

Figure 2: Schematic illustration of intercellular cholesterol transport from astrocytes to neurons. Astrocytes secrete apoE-rich lipoproteins. ApoE uptake is realized by the endocytosis mediated by LDLr family members, whose expression and membrane exposition is particularly high in neurons. Subsequently, the activity of NPC1 and NPC2 leads to the release of free cholesterol from the endosomal/lysosomal system. ATP-binding cassette (ABC) transporters play a relevant function in the shuttling of cholesterol from astrocytes to neurons. Indeed, ABCA1 is abundantly expressed in astrocytes, and exerts a crucial role in the delivery of cholesterol from glia to neurons through apoE-rich particles. ABCA1 expression is strongly regulated by LXRs, whose activation is dependent on 24(S)-hydroxycholesterol. This cholesterol derivative is produced by the activity of CYP46 and also represents the main excretory pathway in the brain. Deregulations of different regulators of cholesterol homeostasis could easily lead to the onset of neurological disorders (red), which are discussed below in this article.

ApoE (apolipoprotein E); ABCA1 (ATP Binding Cassette A1); CYP46 (cholesterol 24S-hydroxylase ); ER (Endoplasmic Reculum); HMGR (3 $\beta$-hydroxy$3 \beta$-methylglutaryl CoA reductase); LXR (Liver X Receptors); LDLr (Low Density Lipoprotein receptor); NPC1 (Niemann-Pick disease type C1 protein); NPC2 (Niemann-Pick disease type C2 protein); SREBP (Sterol Regulatory Element Binding Protein).

Tau proteins exert pivotal roles in neurons, since they bind and stabilize microtubules in axons under normal conditions. Under pathological conditions, tau proteins result to be hyperphosphorylated. This event determines the detachment of tau from microtubules and the formation of insoluble tau aggregates (neurofibrillary tangles, NFTs) which affect the microtubular transport system of neurons.

$\mathrm{A} \beta$ is a toxic peptide, produced by the proteolytic cleavage of the amyloid precursor protein (APP). This enzymatic processing is operated by the activity of $\beta$-secretase (beta-site APP cleaving enzyme 1, BACE1) and the $\gamma$-secretase complex. Rare but penetrant mutations in the genes encoding APP and presenilins 1 and 2 (the catalytic components of the $\gamma$-secretase) are related to early-onset familial $\mathrm{AD}(\mathrm{FAD})$. Even though $\mathrm{AD}$ is strongly associated with the accumulation of extracellular $\mathrm{A} \beta$-containing plaques and the build-up of neuronal NFTs, the specific link between these AD hallmarks and the clinical description of the disorder is not completely understood [39]. 
During the last decade, several findings have highlighted an involvement of cholesterol in $A \beta$ production. In particular, $\beta$ - and $\gamma$-secretase complexes reside in cholesterol-rich lipid rafts, and the enzymatic activity of both the protein complexes are conditioned by the cellular cholesterol content $[40,41]$. The dependence of amyloidogenesis on cholesterol metabolism is also strengthened by the relation between $\mathrm{A} \beta$ production and the rise in cholesteryl-ester levels, which are derived from cholesterol esterification operated by acyl-coenzymeA:cholesterol acyltransferase (ACAT) [42]. Genetic studies underlined further implications for cholesterol in the onset of $\mathrm{AD}$. For example, apoE4 isoform was shown to be a genetic risk factor for late onset $\mathrm{AD}$. Approximately $40 \%$ of $\mathrm{AD}$ individuals present at least one apos 4 allele, which increases the incidence of the disease three-fold in heterozygotes and 15-fold in homozygotes [43]. It is suggested that apoE4 is able to promote $\mathrm{A} \beta$ aggregation and/or reduce the clearance of amyloid plaques [44]. Moreover, it was observed that human apoE4 knock-in mice show a decrease in long-term potentiation, excitatory synaptic transmission and dendritic arborization, which determine impaired synaptic and cognitive functions [45-48]. These experimental data corroborate with clinical evidence, demonstrating that apos 4 homozygosity confers a substantial cognitive function decline in persons aged 35 years or older [49]. The putative connection between cholesterol metabolism and $\mathrm{AD}$ is supported by evidence relating other genes involved in the regulation of cholesterol metabolism and the onset of AD. Two different CYP46 polymorphisms have been associated to $\mathrm{AD}$, although an additional study failed to ascertain this connection [50,51]. Finally, AD-related polymorphisms were also identified for ABCA1. Notably, ABCA1 polymorphisms correlate with an increase in the amount of A $\beta$ in the CSF [52].

The dependence of $A \beta$ production on cholesterol levels indicates that a pharmacological approach focused on the modulation of cholesterol metabolism could reduce the risk of AD. For instance, ACAT inhibition leads to a decrease in the amount of cholesterol esters, thus reducing $A \beta$ secretion [53]. This observation corroborates with the reduction in $A \beta$ load and cognitive decline after genetic ablation of ACAT in a mouse model of $\mathrm{AD}$ [42]. Other evidence suggested that $\mathrm{A} \beta$ production is lowered when $\mathrm{ABCA1}$ transporter is up-regulated [54]. Among the plethora of molecules studied in the attempt to address an effective therapeutic intervention for $\mathrm{AD}$ treatment, statins are the most promising. Lovastatin administration decreases $\mathrm{A} \beta$ formation and increases $\alpha$-secretase activity in brain cell cultures [55,56]. Results obtained from animal models generally confirmed these findings. Chronic simvastatin application is able to lower A $\beta$ in the CSF of guinea pigs, whereas the discontinuation of the pharmacological treatment reverses this effect [41]. Similarly, lovastatin and pravastatin administrations reduce A $\beta$ levels in transgenic mice [57]. Although human studies display variable outcomes, clinical evidence is encouraging, suggesting that statin therapy could be a valuable pharmacological strategy to treat $\mathrm{AD}$ patients. Epidemiological data indicate that individuals undergoing statin therapy have a lower risk of developing $\mathrm{AD}[58,59]$. In addition, simvastatin treatment was shown to arrest cognitive decline in a study performed on a small cohort of $26 \mathrm{AD}$ subjects [60]. On the contrary, the PROspective Study of Pravastatin in the Elderly at Risk (PROSPER) study demonstrated the failure of pravastatin to decrease the incidence of dementia in hypercholesterolemic patients [61]. The discrepancies among results collected in human studies suggest that future investigations should reduce the variability of different parameters, taking into account a deep examination of the criteria for subject selection and of methodological approaches addressed to the assessment of cognitive decline.

\section{Niemann-Pick type $\mathrm{C}$ disease}

Niemann-Pick type C disease (NPC, MIM 257220) is a rare genetic autosomal-recessive neurovisceral disorder caused by a progressive and abnormal intracellular storage of unesterified cholesterol and glycosphingolipids in the endosomal/lysosomal compartments [62]. The pattern of lipid storage is peculiar in the brain with respect to other organs and tissues [63]. The onset of NPC disease is caused by mutations in the NPC1 or NPC2 genes, whose products are involved in the regulation of cholesterol efflux. Both proteins are required for the post-lysosomal/late endosomal transport of cholesterol and glycolipids. Nevertheless, the precise functional role carried out by these two proteins remains unclear, as well as their primary substrates [64]. As far as is known, after LDL cholesteryl ester hydrolysis into lysosomes, NPC2 binds cholesterol. Subsequently, NPC2 transfers the sterol to NPC1, thus determining the exit of free cholesterol from lysosomes [65]. Approximately $95 \%$ of the patients express mutations in the NPC1 gene, whereas the remaining 5\% display mutations in the NPC2 gene. Genetic modification in both genes leads to a defect in the processing and utilization of endocytosis-derived cholesterol. The aberration in intracellular cholesterol homeostasis maintenance is responsible for cholesterol build-up and secondary deregulations in sphingomyelin metabolism in extra neural tissues, that are typical features in NPC individuals. In the CNS, the alterations in lipid metabolism caused by mutations in NPC genes lead to neuronal storage with mega-neurite formation, extensive growth of ectopic dendrites, neurofibrillary tangles, neuroinflammation and neuroaxonal dystrophy, which are fundamental neuropathological hallmarks of the disease [66]. Notably, the finding that paired helical filament tau in NTFs-rich NPC brains is indistinguishable from paired helical filament tau in AD, is very intriguing: this observation suggests that neurodegenerative events could be, at least in part, similar in both disorders, further sustaining the pivotal involvement of cholesterol in brain physiopathology. During disease progression, neuronal death becomes outstanding, and specifically affects precise brain areas, such as Purkinje cells of the cerebellum. However, the reason for this selective neuronal sensitivity is still not clear [66].

Currently, NPC disease diagnosis is focused on biochemical approaches: for example, different assays are carried out on cultured patient skin fibroblasts, directed to evaluating deregulations in LDL-cholesterol trafficking by cytochemical analysis of accumulated free cholesterol and examination of LDL-induced cholesterol ester formation [67]. 
The clinical description of NPC disease is highly heterogeneous [62,68]. The onset of the disease is also extremely variable, ranging from the perinatal period to adulthood. Early pathological manifestations may be of hepatic, pulmonary, neurological or psychiatric nature. The systemic and neurological aspects of the disorder often possess independent courses. All NPC individuals are characterized by neurological and/or psychiatric manifestations. Hence, the most current classification of NPC disease is based on the age of onset of the neuropsychiatric symptoms, which are inversely associated with the lifespan of the patients. Among the neuropsychiatric clinical features, NPC disease is characterized by cerebellar ataxia, movement disorders, cataplexy, epileptic seizure, dystonia and progressive dementia [63]. Presently, an efficient pharmacological treatment for this fatal disorder is not accessible, and only supportive or palliative treatments for the management of precise clinical outcomes are present. Therapies focused on the molecular pathology of NPC were studied in cell culture and animal models. Principally, the prospective action of neurosteroids, cholesterol-sequestering agents (e.g., cyclodextrin), and antioxidant compounds, such as N-butyldeoxynojirimycin were deeply analyzed. Cyclodextrin treatment appears a promising therapeutic intervention, even though different findings underline putative limitations because of the low capability of the drug to cross the BBB following systemic administration. Cyclodextrin decreases the neurodegenerative process and strongly extends the lifespan of mice models of NPC disease, hypothesizing that this molecule could be considered a prospective pharmacological approach for the treatment of NPC patients. However, the specific molecular mechanisms by which cyclodextrin mediates these positive effects are still unknown [69]. The most important advancement in the management of neurological outcomes has been the development of N-butyldeoxynojirimycin. This molecule is particularly promising because of its high $\mathrm{BBB}$ penetration. The reduction in glycosphingolipid accumulation mediated by N-butyldeoxynojirimycin could delay the neurological symptomatology and ameliorate the life expectancy of patients affected by NPC disease [70].

\section{Huntington's disease}

Huntington's disease (HD) is an autosomal-dominant genetic disorder characterized by a progressive neurodegeneration. The emblematic clinical outcomes of this pathology are dysfunctions in motor coordination, cognitive impairment and psychiatric disturbances, which lead to progressive dementia and death $\sim 15-20$ years after disease onset [71]. The elongated CAG repeat on the short arm of chromosome 4p16.3 in the huntingtin gene (encoding for the huntingtin protein, HTT) represents the cause of HD. The disorder is associated with 36 CAG repeats or more, and clinical manifestation occurs when the number of trinucleotide repeats expansion is over 40 [72]. The $\mathrm{htt}$ gene encodes for $348-\mathrm{kDa}$ multidomain protein that possesses a polymorphic glutamine/ proline-rich domain at its amino-terminus. The anomalous long polyQ domain leads to abnormal conformational changes of HTT, which reflect in the production of intracellular aggregates [71]. HTT is expressed in the nucleus, cell body, dendrites and nerve terminals of neurons, and is also associated with a number of intracellular organelles such as ER and mitochondria. It is suggested that HTT has a key role in vesicle transport and/or cytoskeletal anchoring, as it takes part to the dynactin complex and co-localizes with microtubules directly interacting with $\beta$-tubulin. It has also been demonstrated that HTT regulates other cellular processes such as clathrin-mediated endocytosis, neuronal transport and postsynaptic signaling [73]. In addition, HTT seems to protect nerve cells from apoptotic events, thus exerting a crucial function in cell survival [74]. Mutant HTT is abnormally cleaved and generates toxic fragments with unusual compact $\beta$-sheet conformation. The inhibition of proteasomes, chaperones and autophagy, which determine a build-up of proteins and other cellular elements with altered conformation, seem to mediate the toxic effects exerted by mutated HTT [72].

Recently, the prospective role of cholesterol imbalance in determining the pathological aspects of HD has attracted increasing interest. Experimental data highlight that mutated HTT is responsible for the transcriptional suppression of genes involved in cholesterol and fatty acid synthesis in striatal cell lines with inducible expression of mutant HTT [75]. Other results obtained from in vivo studies confirm this finding, as downregulation of cholesterologenic genes, reduction in HMGR activity and the subsequent fall in sterol content were observed in adult brains from 4 different HD animal models (R6/2 mice, YAC mice, HdhQ111 knock-in mice and transgenic HD rats). Furthermore, it is interesting to note that HMGR activity and the concentration of cholesterol precursors are reduced before the onset of cognitive impairments, whereas the decrease in the amount of cholesterol is only present during advanced symptomatic stages of the disease [76,77]: these data suggest that a defect in the regulation of cholesterol biosynthesis could be involved, at least in part, in the pathogenesis of HD.

The signal transduction pathway at the root of cholesterol biosynthesis suppression in HD is probably linked to an altered regulation of SREBP activation. Experimental evidence demonstrates that SREBP interacts with HTT, and the activation of this transcription factor is reduced in cell culture and animal models of $\mathrm{HD}$ [78,79]. Although a variety of in vitro and in vivo studies have highlighted the connection between cholesterol metabolism and HD pathophysiology, only few researches were aimed at evaluating brain cholesterol metabolism in the brains of individuals affected by HD. The expression of cholesterologenic genes are reduced in post-mortem caudate from human HD patients with respect to age-matched control brains, corroborating with previous data obtained on HD animal models [80]. Moreover, recent data show that sterol content isolated from caudate post-mortem is increased in severe grade $\mathrm{HD}$ [81], hypothesizing that cholesterol biosynthesis is inhibited through a negative feedback mechanism activated by the accumulation of sterol molecules. However, this specific finding is not in accordance with that found in animal studies, which indicates that the amount of sterols is lowered in murine models of HD [76]. The precise explanation of this discrepancy is currently not clarified. The extensive cell-to-cell variability in human brain specimens, not considered in this study, could be a possible explanation [34]. Finally, HD patients were shown to have reduced 24(S)-hydroxycholesterol levels, the major catabolite 
responsible for cholesterol excretion from the CNS. This finding supports the idea that cholesterol turnover is impaired in HD brains. The decrease in plasma 24(S)-hydroxycholesterol is associated with a reduction in the caudate volume of HD individuals [82], suggesting that the alteration in cholesterol homeostasis maintenance could be implicated in the development of HD pathology.

Even though there is currently no cure for HD, different therapeutic approaches are available for treating symptoms, in the attempt to improve the quality of life [72]. Evidences that cholesterol imbalance is present in HD, led to the hypothesis that a pharmacological treatment addressed to cholesterol metabolism could, at least in part, exert beneficial effects in the management of the disease. For instance, as omega-3 are able to regulate SREBP activation, which is altered in HD, it is proposed that the application of these polyunsaturated fatty acids could ameliorate the symptomatology of HD patients [83].

\section{Autism spectrum disorders}

Autism spectrum disorders (ASD) are a group of developmental disabilities characterized by significant abnormalities in social interaction, difficulties in communication, stereotyped behaviors and interests, and in some cases, delays in cognitive function. Unfortunately, the specific molecular mechanisms underlying these neurodevelopmental disorders still remain to be elucidated. However, a variety of genetic, infectious, metabolic and environmental factors seem to contribute to the onset of ASD [84]. ASD are often associated with peculiar inherited diseases, such as fragile $\mathrm{X}$ syndrome, tuberous sclerosis, phenylketonuria and lipid alterations as appeared in Smith-Lemli-Opitz syndrome (SLOS) [85]. SLOS is a multiple congenital malformation syndrome, and one of the most prevailing autosomal recessive diseases, occurring in approximately 1 of 20,000 people. The onset of the disease is caused by exceedingly concentrated amounts of 7-dehydrocholesterol (7-DHC), roughly 1000-fold higher than in unaffected humans. The alteration in 7-DHC is consistent with mutations in 7-dehydrocholesterol reductase (DHCR7), which impair the activity of the enzyme. This integral membrane enzyme is responsible for the final step of cholesterol biosynthetic pathway, which requires NADPH as a cofactor to catalyze the conversion of 7-DHC to cholesterol [86].

The toxic effect of 7-DHC and of its oxidation products is currently under investigation [87]. However, 7-DHC appears to modify intracellular cholesterol transport and enhance HMGR degradation, contributing to a reduction in sterol biosynthesis in SLOS patients. The resulting modifications in the sterol pattern impair the chemical and biological properties of cellular membranes. Indeed, the substitution of 7-DHC for cholesterol into cell membranes worsens membrane fluidity, lipid raft stability, and localization of membrane proteins [88].

The build-up of 7-DHC in SLOS patients is responsible for a particular phenotype, which is characterized by microcephaly, mental retardation, affective disorders, mood changes, growth abnormalities, endocrine malfunction, and heart and kidney malformations [89,90]. Furthermore, cognitive deficits are present in SLOS, even though the phenotypic heterogeneity is also reflected in the specific degree of cognitive abilities observed in each patient [91]. Interestingly, SLOS behavioral phenotype also includes different ASD characteristics, such as social alterations, language difficulties and stereotyped behaviors. Clinical reports demonstrated that approximately three quarters of the children affected by SLOS possess some variant of autism, suggesting the assumption that mutations in a single gene could cause ASD [92]. Increasing evidence indicates that SLOS could be a valuable model to delve deeper into the genetic mechanisms at the root of ASD [93]. In particular, imbalance in cholesterol biosynthesis in SLOS impairs dendrite differentiation, myelination, steroid hormone synthesis and the functionality of neurotransmitter receptors. As a consequence, it is possible to speculate that disruption of these processes could lead to the onset of different ASD features.

This hypothesis is sustained by the fact that a high percentage of ASD children have abnormal plasma cholesterol levels [94]. Elevation in total cholesterol and LDL cholesterol was also found in individuals with Asperger syndrome, another neurodevelopmental disorder belonging to ASD [95].

Rett syndrome (RTT) further supports the connection between cholesterol homeostasis disruption and ASD. RTT is a severe autism-like disorder that affects almost exclusively females. Even though it is a relatively rare condition, RTT is one of the most common causes of mental retardation in females. Up to now, 14 detectable mutations in the X-linked methyl-CpG-binding protein 2 gene (MeCP2) are found to be responsible for the onset of the disease. MeCP2 is a key transcription regulator involved in gene silencing via methylation-dependent chromatin remodeling [96]. Recent findings demonstrated that mutations in the MeCP2 gene are able to disrupt cholesterol metabolism in brains and livers of transgenic mice, whereas simvastatin treatment ameliorates the symptomatology and the behavioral abnormalities related to the disease [97]. In addition, serum total cholesterol, LDL-cholesterol and HDL-cholesterol were higher in RTT patients if compared with age-matched healthy females. Notably, the increase in HDLcholesterol is accompanied by a strong decrease in SRB1 expression, which is responsible for the selective uptake of plasma HDL particles [98].

\section{Mood and affective disorders}

A variety of research indicates that cholesterol imbalance could be implicated in different mood disorders. It is becoming clear that low cholesterol levels lead to an increased risk of depressive disorders [99-103], and the amount of plasma cholesterol correlates wi- 
th the severity of depressive symptoms in depressed individuals [102,104,105], elderly [100] and middle-aged women [106]. These data are strengthened by the fact that cholesterol lowering medications are able to increase the onset of depressive states [107].

Deregulation in cholesterol metabolism is further exacerbated in suicidal depressed patients. Alteration in cholesterol levels is often associated with increased inclination to commit suicide [104,108-110]. For instance, HDL-cholesterol is specifically decreased in depressed suicide attempters [109]; whereas other epidemiological observations reported a tight connection between low plasma cholesterol levels and suicidal behaviors [111-114]. How plasma cholesterol influences the onset of depressive disorders is still unknown. Considering the incapability of this lipid to cross the BBB, further investigations are required in order to better comprehend the molecular basis of these physiopathological outcomes. However, we speculate that imbalance in plasma cholesterol could reflect an alteration in cholesterol homeostasis maintenance in the CNS. This hypothesis appears to be supported by other studies, which highlighted that the amount of brain cholesterol is reduced in subjects with major depression and other affective disorders $[115,116]$. In addition, the grey-matter of violent suicide completers is characterized by low cholesterol content [117]; and suicidal behaviors are more frequent among carriers of SLOS, an inherited and autosomal-recessive disorder resulting from a genetic breakdown in cholesterol biosynthesis in all organs, including the brain [118]. Although the majority of literature data reports low cholesterol levels in suicide and depressive disorders, it is important to highlight that other studies failed to find a relationship between cholesterol and depressed mood $[119,120]$.

Increasing evidence also indicates the involvement of cholesterol in the onset of anxiety behaviors. Notably, individuals affected by post-traumatic stress disorder, panic disorder, obsessive-compulsive disorder and generalized anxiety disorder are shown to have high serum cholesterol levels [121-124]. On the contrary, other clinical data reported an inverse correlation between plasma cholesterol and anxiety $[103,125]$. These observations are in agreement with more recent published data, which have shown that hypolipidemic treatment with statins is associated with anxiety states both in humans and animal models [103,125-127].

Besides depressive and anxiety disorders, impairments in cholesterol metabolism have also been implicated in severe irritability and violence $[128,129]$. For instance, plasma cholesterol was found to be high in presence of hostility and angry affect [130]. Differently, cohort, case-control, and cross-sectional studies demonstrated increased violent behaviors in individuals with low plasma cholesterol levels or in patients receiving cholesterol-lowering therapies [128]: the discrepancy among these findings suggests that future investigations should take into account a deep analysis of the different subtypes of aggressive behavior and a better definition of the diagnostic characteristics [131].

Most of the hypothesis linking cholesterol imbalance and affective disorders involve deregulations in serotonin neurotransmission. In particular, cholesterol could influence the cell membrane fluidity and integrity, thus inducing impairments in serotonin activity. Accumulation or depletion of cholesterol is responsible for the reduction in the amount of brain serotonin, decrease in serotonin transporter activity and blockade of serotonin receptor 1A transduction pathway [132-134]. These observations indicate that an optimal concentration of cholesterol is required to guarantee physiological functions in the CNS, suggesting that the excess or the reduction of this molecule could easily lead to mood alterations. However, despite this evidence, the specific mechanisms underlying the susceptibility of developing mood disorders in dependence of cholesterol are still under active investigation.

\section{Conclusions}

Sufficient information is now available to understand the basis of cholesterol metabolism in the CNS, where this lipid fulfills structural and functional tasks, ranging from synaptic plasticity to saltatory conduction of action potentials. It is not surprising that an optimal cholesterol concentration is required for numerous neurophysiological processes. Outside the brain, cholesterol supply is mainly assured by the uptake of circulating lipoproteins, which are produced by the liver or the intestine. The incapability to transport lipoprotein particles inside the CNS, due to the anatomical constitution of the BBB, obligates brain cells to regulate cholesterol concentration in a different manner. Cholesterol delivery from astrocytes to neurons represents a pivotal mechanism to maintain cholesterol homeostasis in the brain. It is possible that impairments in cholesterol metabolism could reflect in the development of different neurological and neuropsychiatric disorders (Table 1). The studies reviewed here highlight an intriguing relationship between cholesterol and neurodegenerative events such as AD, HD, and NPC disease, while other clinical evidence shows emerging roles for this lipid in the onset of ASD. However, although a great knowledge about the pathophysiological role of cholesterol in the CNS has been reached, literature data is far from being convincing. Indeed, the presence of contradictory results indicates that further investigations are required to delve deeper into the causality between cholesterol alteration and brain disorders. For instance, considering the well-accepted theory of brain cholesterol isolation, the influence of plasma cholesterol in the onset of mood disorders and ASD remains to be elucidated. A better comprehension of the basic molecular mechanisms by which imbalance in cholesterol homeostasis is linked to neurologic and neuropsychiatric diseases could provide useful information for designing novel and effective therapeutic approaches.

\section{Akcnowledgments}

We thank Dr Marco Lecis (Department of Experimental Medicine and Surgery, University of Rome "Tor Vergata", Rome, Italy) for the helpful comments and suggestions. 


\begin{tabular}{|c|c|c|c|c|}
\hline $\begin{array}{c}\text { Neurological/neuropsychiatric } \\
\text { disorder }\end{array}$ & $\begin{array}{l}\text { Cholesterol content } \\
\text { compared to controls }\end{array}$ & Species & Tissue & Reference \\
\hline \multirow{3}{*}{ Alzheimer's disease } & Increased & Rat & $\begin{array}{l}\text { Brain (primary neuron } \\
\text { culture) }\end{array}$ & 135,136 \\
\hline & Increased & Human & Brain & 137 \\
\hline & Increased & Human & Blood & 138 \\
\hline \multirow[t]{2}{*}{ Niemann-Pick type $\mathrm{C}$ disease } & Increased & Human & Skin, liver, brain & 63,139 \\
\hline & Increased & Mouse & Brain & 140 \\
\hline \multirow[t]{2}{*}{ Huntington's disease } & Decreased & Mouse & Brain & 76,77 \\
\hline & Increased & Human & Brain & 81 \\
\hline \multirow[b]{2}{*}{ Smith-Lemli-Opitz syndrome } & Decreased & Mouse & Brain, liver & 141 \\
\hline & Decreased & Human & $\begin{array}{l}\text { Brain, liver, adipose, } \\
\text { thymus, muscle, adrenal, } \\
\text { blood }\end{array}$ & 142 \\
\hline \multirow{3}{*}{ Autism spectrum disorders } & Decreased & Human & Blood & 94 \\
\hline & Increased & Human & Blood & 95,98 \\
\hline & Increased & Mouse & Brain & 97 \\
\hline \multirow{3}{*}{$\begin{array}{l}\text { Depression and suicidal behav- } \\
\text { iors }\end{array}$} & Decreased & Human & Blood & $99,100,101,102,103,109,111,112,113,114$ \\
\hline & Decreased & Human & Brain & $115,116,117$ \\
\hline & No changes & Human & Blood & 119,120 \\
\hline \multirow{3}{*}{ Anxiety } & Increased & Human & Blood & $121,122,123,124$ \\
\hline & Decreased & Human & Blood & 103,125 \\
\hline & Decreased & Mouse, Rat & Blood & 126,127 \\
\hline
\end{tabular}

Table 1: Summary of different experimental data linking alterations in cholesterol content to the onset of neurological/neuropsychiatric disorders.

\section{References}

1. Segatto M, Leboffe L, Trapani L, Pallottini V (2014) Cholesterol Homeostasis Failure in the Brain: Implications for Synaptic Dysfunction and Cognitive Decline. Curr Med Chem [Epub ahead of print].

2. Repa JJ, Lund EG, Horton JD, Leitersdorf E, Russell DW, et al. (2000) Disruption of the sterol 27-hydroxylase gene in mice results in hepatomegaly and hypertriglyceridemia. Reversal by cholic acid feeding. J Biol Chem 275: 39685-92.

3. Dietschy JM, Turley SD (2004) Thematic review series: brain Lipids. Cholesterol metabolism in the central nervous system during early development and in the mature animal. J Lipid Res 45: 1375-97.

4. Burger K, Gimpl G, Fahrenholz F (2000) Regulation of receptor function by cholesterol. Cell Mol Life Sci 57: $1577-92$.

5. Weibel GL, Drazul-Schrader D, Shivers DK, Wade AN, Rothblat GH, et al. (2014) Importance of evaluating cell cholesterol influx with efflux in determining the impact of human serum on cholesterol metabolism and atherosclerosis. Arterioscler Thromb Vasc Biol 34: 17-25.

6. Tso P, Drake DS, Black DD, Sabesin SM (1984) Evidence for separate pathways of chylomicron and very low-density lipoprotein assembly and transport by rat small intestine. Am J Physiol 247: G599-610.

7. D B Zilversmit (1965) The composition and structure of lymph chylomicrons in dog, rat, and man. J Clin Invest 44: 1610-22.

8. Ockner RK, Manning JA (1974) Fatty acid-binding protein in small intestine. Identification, isolation, and evidence for its role in cellular fatty acid transport. J Clin Invest 54: 326-38.

9. Zannis VI, Chroni A, Kypreos KE, Kan HY, Cesar TB, et al. (2004) Probing the pathways of chylomicron and HDL metabolism using adenovirus-mediated gene transfer. Curr Opin Lipidol 15: 151-66.

10. Martini C, Pallottini V (2007) Cholesterol: from feeding to gene regulation. Genes Nutr 2: 181-93.

11. Dietschy JM (1984) Regulation of cholesterol metabolism in man and in other species. Klin Wochenschr 62: 338-45.

12. Goldstein JL, Brown MS (1990) Regulation of the mevalonate pathway. Nature 343: 425-30.

13. Rozman D, Monostory K (2010) Perspectives of the non-statin hypolipidemic agents. Pharmacol Ther 127: 19-40.

14. Ingebritsen TS (1983) Protein phosphorylation and the hormonal control of hepatic cholesterol synthesis. Biochem Soc Trans 11: 644-6.

15. Xu F, Rychnovsky SD, Belani JD, Hobbs HH, Cohen JC, et al. (2005) Dual roles for cholesterol in mammalian cells. Proc Natl Acad Sci U S A $102: 14551-6$.

16. Espenshade PJ, Hughes AL (2007) Regulation of sterol synthesis in eukaryotes. Annu Rev Genet 41: 401-27.

17. Horton JD, Goldstein JL, Brown MS (2002) SREBPs: activators of the complete program of cholesterol and fatty acid synthesis in the liver. J Clin Invest 109: 1125-31.

18. Sever N, Yang T, Brown MS, Goldstein JL, DeBose-Boyd RA (2003) Accelerated degradation of HMG CoA reductase mediated by binding of insig-1 to itsbsterol-sensing domain. Mol Cell 11: 25-33.

19. Boekholdt SM, Arsenault BJ, Hovingh GK, Mora S, Pedersen TR, et al. (2013) Levels and changes of HDL cholesterol and apolipoprotein A-I in relation to risk of cardiovascular events among statin-treated patients: a meta-analysis. Circulation 128: 1504-12.

20.Istvan ES, Deisenhofer J (2001) Structural mechanism for statin inhibition of HMG-CoA reductase. Science 292: 1160-4. 
21. Orth M, Bellosta S (2012) Cholesterol: its regulation and role in central nervous system disorders. Cholesterol 2012: 292598

22. Allen JA, Halverson-Tamboli RA, Rasenick MM (2006) Lipid raft microdomains and neurotransmitter signalling. Nat Rev Neurosci 8: 128-40.

23. Sooksawate T, Simmonds MA (2001) Effects of membrane cholesterol on the sensitivity of the GABA(A) receptor to GABA in acutely dissociated rat hippocampal neurones. Neuropharmacology 40: 178-84.

24. Hering H, Lin CC, Sheng M (2003) Lipid rafts in the maintenance of synapses, dendritic spines, and surface AMPA receptor stability. J Neurosci 23: 3262-71.

25. Deutsch JW, Kelly RB (1981) Lipids of synaptic vesicles: relevance to the mechanism of membrane fusion. Biochemistry 20: $378-85$.

26. Renkin EM (1977) Multiple pathways of capillary permeability. Circ Res 41: 735-43.

27. Rubin LL, Staddon JM (1999) The cell biology of the blood-brain barrier. Annu Rev Neurosci 22: 11-28.

28. Saito M, Benson EP, Saito M, Rosenberg A (1987) Metabolism of cholesterol and triacylglycerol in cultured chick neuronal cells, glial cells, and fibroblasts: accumulation of esterified cholesterol in serum-free culture. J Neurosci Res 18: 319-25.

29. Segatto M, Di Giovanni A, Marino M, Pallottini V (2013) Analysis of the protein network of cholesterol homeostasis in different brain regions: an age and sex dependent perspective. J Cell Physiol 228: 1561-7.

30. Segatto M, Trapani L, Lecis C, Pallottini V (2012) Regulation of cholesterol biosynthetic pathway in different regions of the rat central nervous system. Acta Physiol (Oxf) 206: 62-71.

31. Pfrieger FW (2003) Outsourcing in the brain: do neurons depend on cholesterol delivery by astrocytes? Bioessays 25: 72-8.

32. Slezak M, Pfrieger FW (2003) New roles for astrocytes: regulation of CNS synaptogenesis. Trends Neurosci 26: 531-5.

33. Nieweg K, Schaller H, Pfrieger FW (2009) Marked differences in cholesterol synthesis between neurons and glial cells from postnatal rats. J Neurochem 109: 125-34.

34. Valenza M, Cattaneo E (2011) Emerging roles for cholesterol in Huntington's disease. Trends Neurosci 34: 474-86.

35. Bjorkhem I, Meaney S (2004) Brain cholesterol: long secret life behind a barrier. Arterioscler Thromb Vasc Biol 24: 806-15.

36. Oram JF, Heinecke JW (2005) ATP-binding cassette transporter A1: a cell cholesterol exporter that protects against cardiovascular disease. Physiol Rev 85: 1343-72.

37. Wang Z, Li DD, Liang YY, Wang DS, Cai NS (2002) Activation of astrocytes by advanced glycation end products: cytokines induction and nitric oxide release. Acta Pharmacol Sin 23: 974-80.

38. Hashimoto M, Rockenstein E, Crews L, Masliah E (2003) Role of protein aggregation in mitochondrial dysfunction and neurodegeneration in Alzheimer's and Parkinson's diseases. Neuromolecular Med 4: 21-36.

39. McIntire LB, Berman DE, Myaeng J, Staniszewski A, Arancio O, et al. (2011) Reduction of synaptojanin 1 ameliorates synaptic and behavioral impairments in a mouse model of Alzheimer's disease. J Neurosci 32: 15271-6.

40. Cordy JM, Hussain I, Dingwall C, Hooper NM, Turner AJ (2003) Exclusively targeting beta-secretase to lipid rafts by GPI-anchor addition up-regulates beta-site processing of the amyloid precursor protein. Proc Natl Acad Sci U S A 100: 11735-40.

41. Xiong H, Callaghan D, Jones A, Walker DG, Lue LF, et al. (2008) Cholesterol retention in Alzheimer's brain is responsible for high beta- and gamma-secretase activities and Abeta production. Neurobiol Dis 29: 422-37.

42. Bryleva EY, Rogers MA, Chang CC, Buen F, Harris BT, et al. (2010) ACAT1 gene ablation increases 24(S)-hydroxycholesterol content in the brain and ameliorates amyloid pathology in mice with AD. Proc Natl Acad Sci U S A 107: 3081-6.

43. Blennow K, de Leon MJ, Zetterberg H (2006) Alzheimer's disease. Lancet 368: 387-403.

44. Wolozin B (2004) Cholesterol and the biology of Alzheimer's disease. Neuron 41: 7-10.

45. Trommer BL, Shah C, Yun SH, Gamkrelidze G, Pasternak ES, et al. (2004) ApoE isoform affects LTP in human targeted replacement mice. Neuroreport 15: 2655-8.

46. Levi O, Jongen-Relo AL, Feldon J, Roses AD, Michaelson DM (2003) ApoE4 impairs hippocampal plasticity isoform-specifically and blocks the environmental stimulation of synaptogenesis and memory. Neurobiol Dis 13: 273-82.

47. Wang C, Wilson WA, Moore SD, Mace BE, Maeda N, et al. (2005) Human apoE4-targeted replacement mice display synaptic deficits in the absence of neuropathology. Neurobiol Dis 18: 390-8.

48. Zhong N, Scearce-Levie K, Ramaswamy G, Weisgraber KH (2008) Apolipoprotein E4 domain interaction: synaptic and cognitive deficits in mice. Alzheimers Dement 4: 179-92.

49. Izaks GJ, Gansevoort RT, van der Knaap AM, Navis G, Dullaart RP, et al. (2011) The association of APOE genotype with cognitive function in persons aged 35 years or older. PLoS One 6: e27415.

50. Desai P, DeKosky ST, Kamboh MI (2002) Genetic variation in the cholesterol 24-hydroxylase (CYP46) gene and the risk of Alzheimer's disease. Neurosci Lett 328: 9-12.

51. Kolsch H, Lutjohann D, Ludwig M, Schulte A, Ptok U, et al. (2002) Polymorphism in the cholesterol 24S-hydroxylase gene is associated with Alzheimer's disease. Mol Psychiatry 7: 899-902.

52. Wollmer MA, Streffer JR, Lutjohann D, Tsolaki M, Iakovidou V, et al. (2003) ABCA1 modulates CSF cholesterol levels and influences the age at onset of Alzheimer's disease. Neurobiol Aging 24: 421-6.

53. Puglielli L, Konopka G, Pack-Chung E, Ingano LA, Berezovska O, et al. (2001) Acyl-coenzyme A: cholesterol acyltransferase modulates the generation of the amyloid beta-peptide. Nat Cell Biol 3: 905-12.

54. Sun Y, Yao J, Kim TW, Tall AR (2003) Expression of liver X receptor target genes decreases cellular amyloid beta peptide secretion. J Biol Chem 278: 27688-94. 55. Kojro E, Gimpl G, Lammich S, Marz W, Fahrenholz F (2001) Low cholesterol stimulates the nonamyloidogenic pathway by its effect on the alpha -secretase ADAM 10. Proc Natl Acad Sci U S A 98: 5815-20.

56. Buxbaum JD, Geoghagen NS, Friedhoff LT (2001) Cholesterol depletion with physiological concentrations of a statin decreases the formation of the Alzheimer amyloid Abeta peptide. J Alzheimers Dis 3: 221-9.

57. Chauhan N, Wang KC, Wegiel J, Malik MN (2004) Walnut extract inhibits the fibrillization of amyloid beta-protein, and also defibrillizes its preformed fibrils. Curr Alzheimer Res 1: 183-8.

58. Jick H, Zornberg GL, Jick SS, Seshadri S, Drachman DA (2000) Statins and the risk of dementia. Lancet 356: 1627-31.

59. Wolozin B, Kellman W, Ruosseau P, Celesia GG, Siegel G (2000) Decreased prevalence of Alzheimer disease associated with 3-hydroxy-3-methyglutaryl coenzyme A reductase inhibitors. Arch Neurol 57: 1439-43. 
60. Simons K, Ehehalt R (2002) Cholesterol, lipid rafts, and disease. J Clin Invest 110: 597-603.

61. Shepherd J, Blauw GJ, Murphy MB, Bollen EL, Buckley BM, et al. (2002) Pravastatin in elderly individuals at risk of vascular disease (PROSPER): a randomised controlled trial. Lancet 360: 1623-30.

62. Vanier MT, Millat G (2003) Niemann-Pick disease type C. Clin Genet 64: 269-81.

63. Sevin M, Lesca G, Baumann N, Millat G, Lyon-Caen O, et al. (2007) The adult form of Niemann-Pick disease type C. Brain 130: $120-33$.

64. Vanier MT, Millat G (2004) Structure and function of the NPC2 protein. Biochim Biophys Acta 1685: 14-21.

65. Vazquez MC, Balboa E, Alvarez AR, Zanlungo S (2012) Oxidative stress: a pathogenic mechanism for Niemann-Pick type C disease. Oxid Med Cell Longev 2012: 205713.

66. Sun X, Marks DL, Park WD, Wheatley CL, Puri V, et al. (2001) Niemann-Pick C variant detection by altered sphingolipid trafficking and correlation with mutations within a specific domain of NPC1. Am J Hum Genet 68: 1361-72.

67. Tang Y, Li H, Liu JP (2010) Niemann-Pick Disease Type C: From molecule to clinic. Clin Exp Pharmacol Physiol 37: 132-40.

68. Patterson MC (2003) A riddle wrapped in a mystery: Understanding Niemann-Pick disease, type C. Neurologist 9: 301-10.

69. . Liu B, Ramirez CM, Miller AM, Repa JJ, Turley SD, et al. (2010) Cyclodextrin overcomes the transport defect in nearly every organ of NPC1 mice leading to excretion of sequestered cholesterol as bile acid. J Lipid Res 51: 933-44.

70. Ribas GS, Pires R, Coelho JC, Rodrigues D, Mescka CP, et al. (2012) Oxidative stress in Niemann-Pick type C patients: a protective role of N-butyl-deoxynojirimycin therapy. Int J Dev Neurosci 30: 439-44.

71. Landles C, Bates GP (2004) Huntingtin and the molecular pathogenesis of Huntington's disease. Fourth in molecular medicine review series. EMBO Rep 5: 958-63.

72. Ross CA, Tabrizi SJ (2011) Huntington's disease: from molecular pathogenesis to clinical treatment. Lancet Neurol 10: 83-98.

73. Harjes P, Wanker EE (2003) The hunt for huntingtin function: interaction partners tell many different stories. Trends Biochem Sci 28: 425-33

74. Rigamonti D, Bauer JH, De-Fraja C, Conti L, Sipione S, et al. (2000) Wild-type huntingtin protects from apoptosis upstream of caspase-3. J Neurosci 20: 3705-13. 75. Sipione S, Rigamonti D, Valenza M, Zuccato C, Conti L, et al. (2002) Early transcriptional profiles in huntingtin-inducible striatal cells by microarray analyses. Hum Mol Genet 11: 1953-65.

76. Valenza M, Leoni V, Karasinska JM, Petricca L, Fan J, et al. (2010) Cholesterol defect is marked across multiple rodent models of Huntington's disease and is manifest in astrocytes. J Neurosci 30: 10844-50.

77. Valenza M, Carroll JB, Leoni V, Bertram LN, Bjorkhem I, et al. (2007) Cholesterol biosynthesis pathway is disturbed in YAC128 mice and is modulated by huntingtin mutation. Hum Mol Genet 16: 2187-98.

78. Valenza M, Rigamonti D, Goffredo D, Zuccato C, Fenu S, et al. (2005) Dysfunction of the cholesterol biosynthetic pathway in Huntington's disease. J Neurosci 25: $9932-9$

79. Okamoto K, Kakuma T, Fukuchi S, Masaki T, Sakata T, et al. (2006) Sterol regulatory element binding protein (SREBP)-1 expression in brain is affected by age but not by hormones or metabolic changes. Brain Res 1081: 19-27.

80. Valenza F, Aletti G, Fossali T, Chevallard G, Sacconi F, et al. (2005) Lactate as a marker of energy failure in critically ill patients: hypothesis. Crit Care 9: 588-93. 81. Del Toro D, Xifro X, Pol A, Humbert S, Saudou F, et al. (2011) Altered cholesterol homeostasis contributes to enhanced excitotoxicity in Huntington's disease. J Neurochem 115: 153-67.

82. Leoni V, Mariotti C, Tabrizi SJ, Valenza M, Wild EJ, et al. (2008) Plasma 24S-hydroxycholesterol and caudate MRI in pre-manifest and early Huntington's disease. Brain 131: 2851-9.

83. Block RC, Dorsey ER, Beck CA, Brenna JT, Shoulson I (2010) Altered cholesterol and fatty acid metabolism in Huntington disease. J Clin Lipidol 4: 17-23. 84. Muhle R, Trentacoste SV, Rapin I (2004) The genetics of autism. Pediatrics. 113: e472-86.

85. Merkens LS, Wassif C, Healy K, Pappu AS, DeBarber AE, et al. (2009) Smith-Lemli-Opitz syndrome and inborn errors of cholesterol synthesis: summary of the 2007 SLO/RSH Foundation scientific conference sponsored by the National Institutes of Health. Genet Med 11: 359-64.

86. Porter FD (2008) Smith-Lemli-Opitz syndrome: pathogenesis, diagnosis and management. Eur J Hum Genet 16: 535-41.

87. DeBarber AE, Eroglu Y, Merkens LS, Pappu AS, Steiner RD (2011) Smith-Lemli-Opitz syndrome. Expert Rev Mol Med 13: e24.

88. Fliesler SJ (2013) Antioxidants: the missing key to improved therapeutic intervention in Smith-Lemli-Opitz syndrome? Hereditary Genet 2: 119.

89. Nowaczyk MJ, Irons MB (2012) Smith-Lemli-Opitz syndrome: phenotype, natural history,and epidemiology. Am J Med Genet C Semin Med Genet 160C: 25062.

90. Diaz-Stransky A, Tierney E (2012) Cognitive and behavioral aspects of Smith-Lemli-Opitz syndrome. Am J Med Genet C Semin Med Genet 160C: 295-300.

91. Mueller C, Patel S, Irons M, Antshel K, Salen G, et al. (2003) Normal cognition and behavior in a Smith-Lemli-Opitz syndrome patient who presented with Hirschsprung disease. Am J Med Genet A 123A: 100-6.

92. Sikora DM, Pettit-Kekel K, Penfield J, Merkens LS, Steiner RD (2006) The near universal presence of autism spectrum disorders in children with Smith-LemliOpitz syndrome. Am J Med Genet Al 140: 1511-8.

93. Aneja A, Tierney E (2008) Autism: the role of cholesterol in treatment. Int Rev Psychiatry 20: 165-70.

94. Tierney E, Bukelis I, Thompson RE, Ahmed K, Aneja A, et al. (2006) Abnormalities of cholesterol metabolism in autism spectrum disorders. Am J Med Genet B Neuropsychiatr Genet 141B: 666-8.

95. Dziobek I, Gold SM, Wolf OT, Convit A (2007) Hypercholesterolemia in Asperger syndrome: independence from lifestyle, obsessive-compulsive behavior, and social anxiety. Psychiatry Res 149: 321-4.

96. Macdonald JL, Verster A, Berndt A, Roskams AJ (2010) MBD2 and MeCP2 regulate distinct transitions in the stage-specific differentiation of olfactory receptor neurons. Mol Cell Neurosci 44: 55-67

97. Buchovecky CM, Turley SD, Brown HM, Kyle SM, McDonald JG, et al. (2013) A suppressor screen in Mecp2 mutant mice implicates cholesterol metabolism in Rett syndrome. Nat Genet 45: 1013-20.

98. Sticozzi C, Belmonte G, Pecorelli A, Cervellati F, Leoncini S, et al. (2013) Scavenger receptor B1 post-translational modifications in Rett syndrome. FEBS Lett 587: 2199-204.

99. De Berardis D, Conti CM, Serroni N, Moschetta FS, Carano A, et al. (2009) The role of cholesterol levels in mood disorders and suicide. J Biol Regul Homeost Agents 23: 133-40. 
100. Morgan RE, Palinkas LA, Barrett-Connor EL, Wingard DL (1993) Plasma cholesterol and depressive symptoms in older men. Lancet 341: 75-9.

101. Maes M, Delanghe J, Meltzer HY, Scharpé S, D'Hondt P, et al. (1994) Lower degree of esterification of serum cholesterol in depression: relevance for depression and suicide research. Acta Psychiatr Scan 90: 252-8.

102. Rafter D (2001) Biochemical markers of anxiety and depression. Psychiatry Res 103: 93-6.

103. Lieberman HR, Kellogg MD, Kramer FM, Bathalon GP, Lesher LL (2012) Lipid and other plasma markers are associated with anxiety, depression, and fatigue. Health Psychol 31: 210-6.

104. Rabe-Jablonska J, Poprawska I (2000) Levels of serum total cholesterol and LDL-cholesterol in patients with major depression in acute period and remission. Med Sci Monit 6: 539-47.

105. Steegmans PH, Hoes AW, Bak AA, Van der Does E, Grobbee DE (2004) Higher prevalence of depressive symptoms in middle-aged men with low serum cholesterol levels. Psychosom Med 62: 205-11.

106. Horsten M, Wamala SP, Vingerhoets A, Orth-Gomer K (1997) Depressive symptoms, social support, and lipid profile in healthy middle-aged women. Psychosom Med 59: 521-8.

107. You H, Lu W, Zhao S, Hu Z, Zhang J (2013) The relationship between statins and depression: a review of the literature. Expert Opin Pharmacother 14: 1467-76. 108. Tatley M, Savage R (2007) Psychiatric adverse reactions with statins, fibrates and ezetimibe: implications for the use of lipid-lowering agents. Drug Saf 30 : 195-201.

109. Maes M, Smith R, Christophe A, Vandooleaghe E, Van Gastel A, et al. (1997) Lower serum high-density lipoprotein cholesterol (HDL-C) in major depression and in depressed men with serious suicidal attempts: relationship with immune-inflammatory markers. Acta Psychiatr Scand 95: 212-21.

110. Papadopoulou A, Markianos M, Christodoulou C, Lykouras L (2013) Plasma total cholesterol in psychiatric patients after a suicide attempt and in follow-up. J Affect Disord 148: 440-3.

111. Atmaca M, Kuloglu M, Tezcan E, Ustundag B, Gecici O, et al. (2002) Serum leptin and cholesterol values in suicide attempters. Neuropsychobiology 45: 124-7. 112. Olié E, Picot MC, Guillaume S, Abbar M, Courtet P (2011) Measurement of total serum cholesterol in the evaluation of suicidal risk. J Affect Disord 133: 234-8. 113. Kim YK, Lee HJ, Yoon DK, Choi SH, et al. (2002) Low serum cholesterol is correlated to suicidality in a Korean sample. Acta Psychiatr Scand 105: 141-8.

114. Ruljancic N, Mihanovic M, Cepelak I (2011) Thrombocyte serotonin and serum cholesterol concentration in suicidal and non-suicidal depressed patients. Prog Neuropsychopharmacol Biol Psychiatry 35: 1261-7.

115. Lütjohann D (2007) Brain cholesterol and suicidal behaviour. Int J Neuropsychopharmacol 10: 153-7.

116. Beasley CL, Honer WG, Bergmann K, Falkai P, Lütjohann D, et al. (2005) Reductions in cholesterol and synaptic markers in association cortex in mood disorders. Bipolar Disord 7: 449-55.

117. Lalovic A, Levy E, Luheshi G, Canetti L, Grenier E, et al. (2007) Cholesterol content in brains of suicide completers. Int J Neuropsychopharmacol 10: 159-66. 118. Lalovic A, Merkens L, Russell L, Arsenault-Lapierre G, Nowaczyk MJ, et al. (2004) Cholesterol metabolism and suicidality in Smith-Lemli-Opitz syndrome carriers. Am J Psychiatry 161: 2123-6.

119. Freedman DS, Byers T, Barrett DH, Stroup NE, Eaker E, et al. (1995) Plasma lipid levels and psychologic characteristics in men. Am J Epidemiol 141: 507-17. 120. McCallum J, Simons L, Simons J, Friedlander Y (1994) Low serum cholesterol is not associated with depression in the elderly: data from an Australian community study. Aust NZ J Med 24: 561-4.

121. Jakovljević M, Reiner Z, Milicić D (2007) Mental disorders, treatment response, mortality and serum cholesterol: a new holistic look at old data. Psychiatr Danub 19: 270-81.

122. Bajwa WK, Asnis GM, Sanderson WC, Irfan A, van Praag HM (1992) High cholesterol levels in patients with panic disorder. Am J Psychiatry 149: 376-8.

123. Kagan BL, Leskin G, Haas B,Wilkins J, Foy D (1999) Elevated lipid levels in Vietnam veterans with chronic posttraumatic stress disorder. Biol Pscyhiatry 45: 374-7.

124. Peter H, Hand I, Hohagen F, Koenig A, Mindermann O, et al. (2002) Serum cholesterol level comparison: control subjects, anxiety disorder patients, and obsessive-compulsive disorder patients. Can J Psychiatry 47: 557-61.

125. Suarez EC (1999) Relations of trait depression and anxiety to low lipid and lipoprotein concentrations in healthy young adult women. Psychosom Med 61: 273-9.

126. Segatto M, Manduca A, Lecis C, Rosso P, Jozwiak A, et al. (2014) Simvastatin treatment highlights a new role for the isoprenoid/cholesterol biosynthetic pathway in the modulation of emotional reactivity and cognitive performance in rats. Neuropsychopharmacology 39: 841-54.

127. Thomas JM, Varkey J, Augustine BB (2014) Association between serum cholesterol, brain serotonin, and anxiety: A study in simvastatin administered experimental animals. Int J Nutr Pharmacol Neurol Dis 4: 69-73.

128. Golomb BA (1998) Cholesterol and violence: is there a connection? Ann Intern Med 128: 478-87.

129. Hillbrand M, reuben TS (1999) Cholesterol and aggression. Aggression and Violent Behav 4: 359-70.

130. Richards JC, Hof A, Alvarenga M (2000) Serum lipids and their relationships with hostility and angry affect and behaviors in men. Health Psychol 19: $393-8$.

131. Troisi A (2009) Cholesterol in coronary heart disease and psychiatric disorders: same or opposite effects on morbidity risk? Neurosci Biobehav Rev 33: 125-32.

132. Saleem S, Haider S, Naqvi F, Tabassum S, Haleem DJ (2011) Long term administration of hmg-coa-reductase inhibitor (simvastatin) affects brain serotonin neurotransmission in male rats. Int J Basic Appl Sci 7: 79-83.

133. Scanlon SM, Williams DC, Schloss P (2001) Membrane cholesterol modulates serotonin transporter activity. Biochemistry 40: $10507-13$.

134. Jafurulla M, Rao BD, Sreedevi S, Ruysschaert JM, Covey DF, et al. (2014) Stereospecific requirement of cholesterol in the function of the serotonin1A receptor. Biochim Biophys Acta 1838: 158-63.

135. Fassbender K, Simons M, Bergmann C, Stroick M, Lutjohann D, et al. (2001) Simvastatin strongly reduces levels of Alzheimer's disease beta -amyloid peptides Abeta 42 and Abeta 40 in vitro and in vivo. Proc Natl Acad Sci U S A 98: 5856-61.

136. Simons M, Keller P, De Strooper B, Beyreuther K, Dotti CG, et al. (1998) Cholesterol depletion inhibits the generation of beta-amyloid in hippocampal neurons. Proc Natl Acad Sci U S A. 95: 6460-4.

137. Heverin M, Bogdanovic N, Lütjohann D, Bayer T, Pikuleva I, et al. (2004) Changes in the levels of cerebral and extracerebral sterols in the brain of patients with Alzheimer's disease. J Lipid Res 45: 186-93.

138. Cedazo-Mínguez A, Ismail MA, Mateos L (2011) Plasma cholesterol and risk for late-onset Alzheimer's disease. Expert Rev Neurother 11: 495-8. 
139. Distl R, Treiber-Held S, Albert F, Meske V, Harzer K, et al. (2003) Cholesterol storage and tau pathology in Niemann-Pick type C disease in the brain. J Pathol 200: 104-11.

140. Reid PC, Sakashita N, Sugii S, Ohno-Iwashita Y, Shimada Y, et al. (2004) A novel cholesterol stain reveals early neuronal cholesterol accumulation in the Niemann-Pick type C1 mouse brain. J Lipid Res 45: 582-91.

141. Fitzky BU, Moebius FF, Asaoka H, Waage-Baudet H, Xu L, et al. (2001) 7-Dehydrocholesterol-dependent proteolysis of HMG-CoA reductase suppresses sterol biosynthesis in a mouse model of Smith-Lemli-Opitz/RSH syndrome. J Clin Invest 108: 905-15.

142. Tint GS, Seller M, Hughes-Benzie R, Batta AK, Shefer S, et al. (1995) Markedly increased tissue concentrations of 7-dehydrocholesterol combined with low levels of cholesterol are characteristic of the Smith-Lemli-Opitz syndrome. J Lipid Res 36: 89-95.

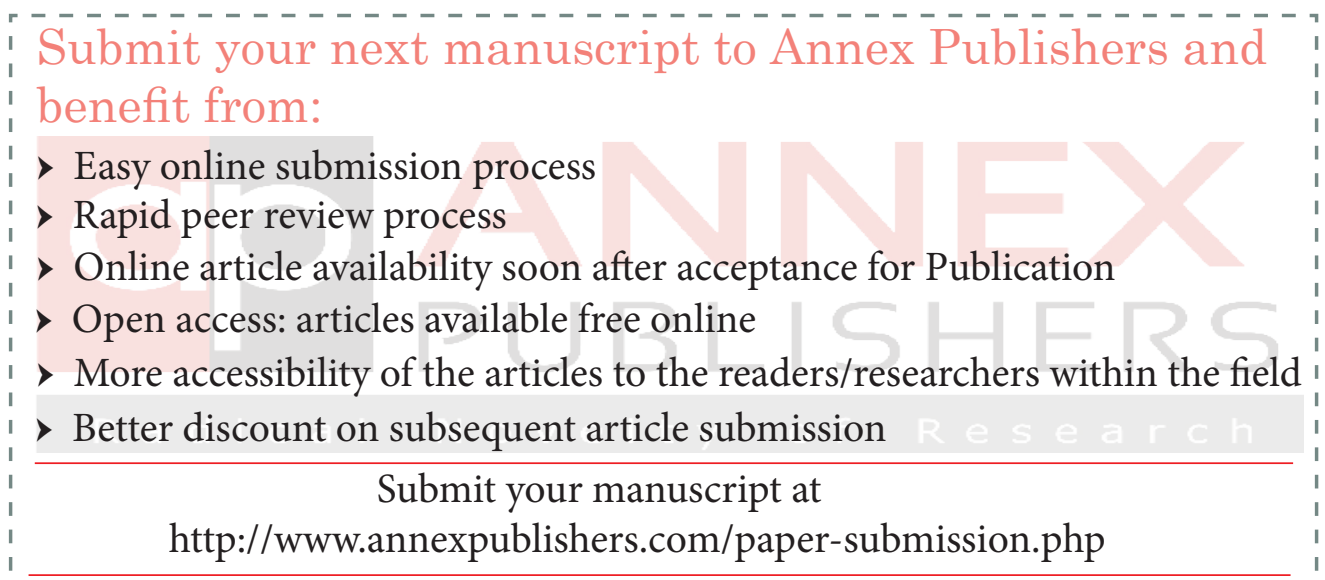

